\title{
Malpresentation of the Fetus in Singleton Pregnancies after In Vitro Fertilization
}

\author{
Sergei Svetoslavov Slavov* (D) \\ Department of Gynecology and Obstetrics, Medical University, Sofia, Bulgaria
}

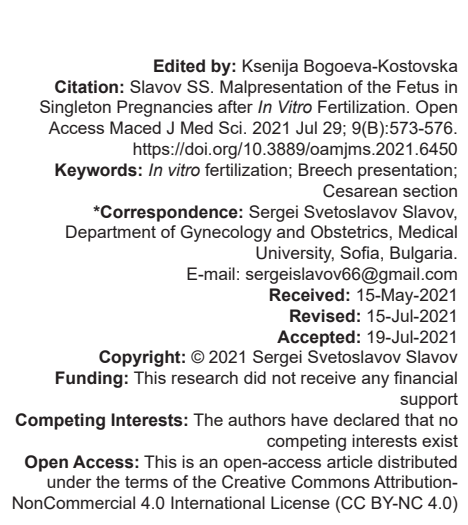

Introduction

The number of women giving birth after in vitro fertilization (IVF) is steadily increasing worldwide. It has been shown in many studies a worse outcome of IVF singleton pregnancies compared to spontaneous singleton pregnancies with a higher risk of complications and adverse perinatal outcomes [1], [2], [3]. The frequency of cesarean section is higher and a higher risk for the newborn is reported [4], [5], [6], [7], [8], [9], [10], [11]. Some studies have found a higher incidence of breech presentation [12], [13], [14], [15], as well as other non-occipital presentations in singleton pregnancies achieved by IVF compared to spontaneous singleton pregnancies [11]. The etiology of breech presentation is not fully understood, but the known risk factors are prematurity, primiparity, advanced maternal age, placenta previa, and uterine anomalies [16]. Breech presentation is associated with an increased rate of delivery by cesarean section, but it is not known whether the management of breech pregnancies in IVF pregnancies differs from that of spontaneously conceived pregnancies.

The aim of this study was to compare IVF and spontaneous singleton pregnancies according to the rate of breech presentation and other non-cephalic presentations, and to and assess the impact of these factors on the mode of delivery.

\section{Materials and Methods}

\section{Study design}

We conducted retrospective study at "Maichin Dom" University Hospital in Sofia, Bulgaria for the period from January 2013 to December 2017.

\section{Cases}

Study cases are 402 singleton IVF pregnancies in women with time to pregnancy more than 1 year- studied group (SG).

\section{Controls}

Study controls are 523 random pregnant women with spontaneous singleton pregnancy without a history of infertility treatment and time to pregnancy less than a year- control group (CG). 


\section{Inclusion criteria}

Singleton pregnancy at the time of birth, available data for the method of conception (spontaneous or IVF), pregnancy ended with birth later than 22 weeks of gestation (w.g.) and/or fetal weight at birth >600 g.

\section{Exclusion criteria}

Multiple pregnancy.

\section{Data collection}

The gestational age during the pregnancy follow-up was determined based on the date of the last menstrual period and/or the date of the embryo transfer. Presentation of the fetus was established by ultrasound and physical examination. Age and parity were examined in all patients. The weight of the newborn was determined immediately after birth by measuring with an accuracy of $10 \mathrm{~g}$.

The Institutional review board of University hospital "Maichin dom", Sofia, Bulgaria approved the collection of data.

\section{Statistical analysis}

Statistical analysis was performed using the SPSS for Windows, v 13. Statistical methods used include descriptive statistical analysis. The counting data were represented by $\mathrm{n}(\%)$. For categorical variables, differences were analyzed with the Chisquared test and Fisher's exact test when appropriate. Statistical significance was established at $p<0.05$.

\section{Results}

The study of 402 pregnant women with singleton IVF pregnancies and 523 pregnant women with spontaneous singleton pregnancies revealed differences in the rate of breech presentation, rate of vaginal deliveries in cases with breech presentation, and differences in the rate of transverse and oblique lie of the fetus (Table 1).

When we analyzed the frequency of breech presentation in different stages of pregnancy in both groups, we found interesting results. In the period before the $28^{\text {th }}$ and before the $32^{\text {nd }}$ week of gestation, no statistical difference was found between the two groups. A statistically significantly higher incidence of breech presentation in the group with singleton pregnancies after IVF was found when the pregnancy was in the interval $32-34^{\text {th }}$ gestational week $(p=0.042)$ and in the interval $34-36^{\text {th }}$ gestational week $(p=0.0013)$.
Table 1: Comparison between IVF singletons and spontaneous pregnancies-malpresentation

\begin{tabular}{llll}
\hline Variable & $\begin{array}{l}\text { IVF pregnancies } \\
\mathrm{n}(\%)\end{array}$ & $\begin{array}{l}\text { Spontaneous } \\
\text { pregnancies } \mathrm{n}(\%)\end{array}$ & p-value \\
\hline Breech presentation & $44 / 402(10.9)$ & $24 / 523(4.6)$ & $<0.001$ \\
Breech presentation <28 w.g. & $2 / 402(0.5)$ & $1 / 523(0.19)$ & $\mathrm{NS}$ \\
Breech presentation <32 w.g. & $8 / 402(1.99)$ & $4 / 523(0.76)$ & $\mathrm{NS}$ \\
Breech presentation <34 w.g. & $11 / 402(2.74)$ & $6 / 523(1.15)$ & 0.042 \\
Breech presentation <37 w.g. & $21 / 402(5.22)$ & $8 / 523(1.53)$ & 0.0013 \\
Vaginal delivery in breech presentation & $1 / 44(2.27)$ & $2 / 24(8.33)$ & $\mathrm{NS}$ \\
Transverse and oblique lie & $4 / 402(0.99)$ & $2 / 523(0.38)$ & $\mathrm{NS}$ \\
\hline IVF: In vitro fertilization, NS: Non-significant. & & &
\end{tabular}

The mean gestational age at delivery among cases with breech presentation in the SG was 250.83 days, while in the CG it was 254.3 days.

In the SG $180(44.8 \%)$ of patients were at age $\leq 35$ years and $222(55.2 \%)$ were $>35$ years old, while in the CG $415(79.3 \%)$ were at age $\leq 35$ years and $108(21.7 \%)$ were $>35$ years old. There was a prevalence of primiparous women in SG - $365(91 \%)$ compared with CG - 303 (58\%).

Despite the large difference in the distribution of cases of breech presentation between the groups, there was no statistically significant difference in the frequency of vaginal birth.

We found four cases $(0.99 \%)$ with transverse and oblique lie of the fetus in IVF group, compared with two cases $(0.38 \%)$ in the control group $(p>0.05)$.

\section{Discussion}

There is some evidence that breech presentation is more common in pregnancies after IVF, but it is not clear to what extent this is due to the method of pregnancy or other factors associated with assisted reproduction. A large study examines whether the mode of conception affects the frequency of breech presentation and whether clinical behavior differs in assisted versus spontaneous conception. Included were 1,209,151 singleton pregnancies, 99\% of which occurred spontaneously and $1 \%$ after IVF. It has been found that breech presentation is about $50 \%$ more common in IVF pregnancies than spontaneous ones, but after equalization of some factors, the most important of which are parity and gestational age at birth, this difference is significantly reduced. Despite this generalized conclusion, the distribution of pregnant women with breech presentation at different gestational ages at birth is interesting. Thus, at gestational age $<28$ weeks it was found almost 2 times higher frequency of births with breech presentation after IVF compared to spontaneous conception. With increasing gestational age, this difference decreases, and after $36 \mathrm{w} . \mathrm{g}$. There is no difference in the frequency of breech presentation according to the method of conception. There is also no difference when comparing IVF to ICSI fertilization. These results are important for clinical practice, as pregnancies after IVF with breech presentation of the 
fetus are much more likely to be delivered by cesarean section than those after spontaneous conception [14].

Our study found more than twice the incidence of breech presentation in IVF singleton pregnancies compared to spontaneous singleton pregnancies. Regarding the distribution of cases according to the gestational age, we came to opposite conclusions. Compared with spontaneous pregnancies, we found a much higher incidence of breech presentation among IVF singleton pregnancies later in pregnancy and no difference between the groups before the pregnancy reached 32 weeks of gestation.

The higher incidence of breech presentation may be one of the factors associated with the higher incidence of cesarean section in IVF singleton pregnancies. In our study, we did not find a statistical difference between spontaneous and IVF singleton pregnancies in terms of the method of delivery in breech presentation, proving a similar frequency of vaginal births in the two groups. Therefore, the role of the increased incidence of breech presentation in IVF is unlikely to play a significant role in increasing the overall incidence of cesarean section in these pregnant women.

A higher incidence of non-occipital presentation in singleton pregnancies after IVF and ovulation induction has been reported by another large study [11]. We found no difference in the incidence of transverse and oblique fetal lie comparing IVF and spontaneous singleton pregnancies.

\section{Conclusion}

Breech presentation is twice as common in singleton pregnancies after IVF as in spontaneous singleton pregnancies. However, this difference in the course of pregnancy does not contribute to a higher incidence of cesarean section in pregnant women after IVF. The reason most likely lies in the high frequency of cesarean section in breech presentation, regardless of the method of achieving pregnancy. Breech presentation in pregnant women with singleton pregnancies after IVF is more common after the $32^{\text {nd }}$ week of gestation. There is no difference between spontaneous and IVF singleton pregnancies in terms of the frequency of transverse and oblique lie of the fetus.

\section{References}

1. Jackson RA, Gibson KA, Wu YW, Croughan M. Perinatal outcomes in singletons following in vitro fertilization: A metaanalysis. Obstet Gynecol. 2004;103(3):551-63. https://doi. org/10.1097/01.aog.0000114989.84822.51

\section{PMid:14990421}

2. Helmerhorst FM, Perquin DA, Donker D, Keirse $M$ Perinatal outcome of singletons and twins after assisted conception: A systematic review of controlled studies. BMJ. 2004;328(7434):261. https://doi.org/10.1136/ bmj.37957.560278.ee

PMid: 14742347

3. McDonald S, Han Z, Mulla S, Murphy K, Beyene J, Ohlsson A et al. Preterm birth and low birth weight among in vitro fertilization singletons: A systematic review and meta-analyses. Eur J Obstetr Gynecol Reprod Biol. 2009;146(2):138-48. https:// doi.org/10.1016/j.ejogrb.2009.05.035

PMid:19577836

4. Vilchez G, Dai J, Hoyos LR, Babbar S, Bahado-Singh RO, Maulik $\mathrm{D}$, et al. Optimal delivery mode in singleton pregnancies conceived after infertility treatment: Is the "precious baby" effect justified? Am J Obstetr Gynecol. 2016;214:445-6. https://doi. org/10.1016/j.ajog.2015.10.906

5. Sazonova A, Kallen K, Thurin-Kjellberg A, Wennerholm UB, Bergh C. Factors affecting obstetric outcome of singletons born after IVF. Hum Reprod. 2011;26(10):2878-86. https://doi. org/10.1093/humrep/der241

6. KallenB, Finnstrom O, NygrenKG, Olausson PO, Wennerholm UB. In vitro fertilization in Sweden: Obstetric characteristics, maternal morbidity and mortality. BJOG. 2005;112(11):1529-35. https:// doi.org/10.1111/j.1471-0528.2005.00745.x

PMid:16225574

7. Maheshwari A, Pandey S, Shetty A, Hamilton M, Bhattacharya S. Obstetric and perinatal outcomes in singleton pregnancies resulting from the transfer of frozen thawed versus fresh embryos generated through in vitro fertilization treatment: A systematic review and meta-analysis. Fertil Steril. 2012;98(2):368-77. https://doi.org/10.1016/j.fertnstert.2012.05.019

PMid:22698643

8. Kostov I, Ingilizova G. Analysis of the results of inspections carried out by executive agency "Medical Audit" of Neonatology practice in Bulgaria. Akusherstvo Ginekol. 2019;58(1):16-20.

9. Kostov I. Assessment of the Impact of Medical Standard in Obstetrics and Gynecology: Organizational, Clinical and Deontological Aspects, Doctoral Thesis, Varna. Varna: Medical Academic Repository of MU-Varna; 2017.

10. Pandey S, Shetty A, Hamilton M, Bhattacharya S, Maheshwari A. Obstetric and perinatal outcomes in singleton pregnancies resulting from IVF/ICSI: A systematic review and metaanalysis. Hum Reprod Update. 2012;18(5):485-503. https://doi. org/10.1093/humupd/dms018

PMid:22611174

11. Silberstein $T$, Sheiner E, Levy A, Herlev A, Saphier O. Perinatal outcome of pregnancies following in vitro fertilization and ovulation induction. J Matern Fetal Neonatal Med. 2014;27(13):1316-9. https://doi.org/10.3109/14767058.2013.85 6415

PMid:24175873

12. Isaksson R, Gissler M, Tiitinen A. Obstetric outcome among women with unexplained infertility after IVF: A matched casecontrol study. Hum Reprod. 2002;17(7):1755-61. https://doi. org/10.1093/humrep/17.7.1755

PMid:12093835

13. Ombelet W, Cadron I, Gerris J, De Sutter P, Bosmans E, Martens G, et al. Obstetric and perinatal outcome of 1655 ICSI and 3974 IVF singleton and 1102 ICSI and 2901 IVF twin births: A comparative analysis. RBM Online. 2005;11(1):76-85. https:// doi.org/10.1016/s1472-6483(10)61302-8

PMid:16102293

14. Romundstad LB, Romundstad PR, Sunde A, von Düring $V$, Skjærven R, Vatten LJ, et al. Assisted fertilization and breech 
delivery: Risks and obstetric management. Hum Reprod. 2009;24(12):3205-10. https://doi.org/10.1093/humrep/dep301

15. Zadori J, Kozinszky Z, Orvos H, Katona M, Pal A, Kovacs I. Dilemma of increased obstetric risk in pregnancies following IVF-ET. J Assist Reprod Genet. 2003;20(6):216-21. https://doi. org/10.1023/a:1022682908307
PMid:12877252

16. Hofmeyr GJ, Hannah ME. Planned caesarean section for term breech delivery. Cochrane Database Syst Rev. 2003;3:CD000166. cd000166.pub2

PMid:12917886 